\title{
Implantação de Reservas Legais: Uma nova perspectiva na conservação dos recursos naturais em paisagem rural ${ }^{1}$
}

\author{
Guilherme F. G. Déstro² \& Sérgio Campos $^{3}$
}

\begin{abstract}
RESU MO
A partir do Código Florestal de 1965, tornou-se obrigatória, a toda propriedade rural, a destinação de parte de suas terras para implantação da Reserva Legal. Quando se faz um diagnóstico pelo Brasil verifica-se que são raras as unidades produtivas que cumprem tal instrumento legal. Este trabalho teve como objetivo geral debater formas para a implantação de Reservas Legais a partir da análise da deterioração ambiental em uma bacia hidrográfica, razão pela qual se realizou um diagnóstico ambiental com base em três diagnósticos correlatos: físico-conservacionista, socioeconômico e qualidade ambiental. Conseguiu-se, através deste estudo, identificar os relevantes fatores de agressão à Bacia estudada e indicar as principais vulnerabilidades às quais a área estava sujeita. Com base nesses resultados, algumas propostas locacionais para Reservas Legais foram debatidas pautando-se em argumentos técnico-científicos voltados para a conservação dos recursos hídricos, solos e biodiversidade. Espera-se, a partir deste estudo, que o meio rural ganhe um novo estímulo para conservação dos recursos naturais, controle da poluição e recuperação ambiental.
\end{abstract}

Palavras-chave: SIG-SPRING, geoprocessamento, sensoriamento remoto, deterioração ambiental

\section{Implantation of Legal Reserves: A new perspective in the conservation of the natural resources in rural landscapes}

\begin{abstract}
According to the Forest Code of 1965 , it is mandatory that every rural property destine part of its land to the establishment of Legal Reserves. When a diagnosis is made over all Brazil, the reality is quite different from what is demanded by law. Therefore, this work, as a general objective, proposes ways of establishing Legal Reserves based on the analysis of the environmental deterioration in a river basin. For this purpose, the environmental deterioration was detected based on three diagnoses: physical-conservational, socioeconomical, and environmental quality. In this way, from a quantitative and qualitative diagnosis, it was possible to identify the main aggressive factors in the studied river basin and to indicate the main vulnerabilities that the area is subjected. According to such diagnosis, some proposals for the establishment of Legal Reserves are discussed here based on scientific arguments aimed at the conservation of water resources, soil and biodiversity. It is hoped, that from this study, the environment receives a new tool for diagnosis, pollution control, recovery and conservation of natural resources.
\end{abstract}

Key words: GIS-SPRING, geoprocessing, remote sensing, environmental deterioration

\footnotetext{
1 Parte da Dissertação apresentada à FCA/UNESP/Botucatu, para obtenção do título de mestre em Agronomia - Área de Concentração em Energia na Agricultura 2 Mestre em Agronomia (FCA/UNESP), Analista Ambiental do Instituto Brasileiro do Meio Ambiente e dos Recursos Naturais Renováveis - IBAMA. Fone: (61) 3316-1198., E-mail: Guilherme.Destro@ibama.gov.br

3 FCA/UNESP, Fazenda Lageado, CP 237, CEP 18603-970, Botucatu,SP. Fone: (14) 3811-7165. E-mail: seca@fca.unesp.br
} 


\section{INTRODUÇÃO}

A Medida Provisória ${ }^{\circ}$ 2.166-67, de 24 de agosto de 2001, que altera o Código Florestal, define Reserva Legal como área localizada no interior de uma propriedade ou posse rural, excetuada a de Preservação Permanente, necessária ao uso sustentável dos recursos naturais, à conservação e reabilitação dos processos ecológicos, à conservação da biodiversidade e ao abrigo e proteção de fauna e flora nativas.

Ainda de acordo com o Código Florestal (LF 4.771/65) e a Medida Provisória $n^{\circ} 2.166-67$, é obrigatório que toda propriedade rural destine parte de suas terras para implantação da Reserva Legal, cuja porcentagem varia de acordo com a região do Brasil: na Amazônia Legal, $80 \%$ da propriedade devem ser mantidos com a vegetação original, quando sob o domínio de floresta, e 35\% quando o bioma predominante for o cerrado. Para as demais regiões brasileiras, um mínimo de $20 \%$ da propriedade devem constituir a Reserva Legal.

A realidade é bem diferente da exigida por Lei. Quando se faz um diagnóstico pelo Brasil, verifica-se que são raras as propriedades rurais que possuem Reservas Legais e, mais difícil ainda, é encontrar uma unidade rural que tenha sua Reserva Legal averbada em um registro de imóveis. Um dos fatores que contribuem para esta realidade é a inexistência de modelos ecológico-econômicos norteadores de ações voltadas para a implantação de Reservas Legais, nos moldes de que trata a Lei (Delalibera et al., 2008).

Mesmo que iniciativas isoladas sejam tomadas, é imprescindível a existência de um planejamento territorial integrado dessas Reservas, para que seus objetivos sejam realmente alcançados. Bertoni \& Lombardi Neto (1990) acreditam que esta planificação racional do uso da terra faz-se necessária para que as explorações agrícolas possam ser conduzidas em bases conservacionistas, levando sempre em consideração os interesses financeiros dos agricultores. Para eles, o planejamento ambiental deve estar apoiado em um levantamento conservacionista que nada mais é que um breve e expedito inventário de todas as condições que podem modificar o uso da terra sejam elas nos meios físico, ecológico ou econômico.

Para Ribeiro (1998), o uso da terra sem um planejamento adequado resultará em empobrecimento do solo e, consequentemente, na queda da produtividade das culturas. A população rural, principal afetada, sentirá os reflexos em seus níveis socioeconômico e tecnológico, tornando-se cada vez mais empobrecida; todavia, com um planejamento do uso da terra inicial efetivo e eficiente é possível proteger a propriedade das erosões e aumentar gradativamente sua capacidade produtiva.

Com a execução de um planejamento integrado, as áreas propícias ao desenvolvimento econômico são caracterizadas de modo a respeitar os ecossistemas da região. O planejamento ambiental acaba se tornando, desta forma, um instrumento essencial para a conciliação entre o crescimento econômico e a exploração racional dos recursos naturais (Tornero, 2000).

Baseado nesses paradigmas, o trabalho teve, como objetivo geral, propor alternativas para implantação de Reservas Legais a partir da análise da deterioração ambiental em ba- cias hidrográficas, visando à conservação dos recursos naturais e ao desenvolvimento sustentável da região.

\section{MATERIAL E MÉTODOS}

A Bacia Experimental do Rio Claro, que divide os municípios de São Manuel e Pratânia, estado de São Paulo, foi escolhida como foco deste estudo de caso. Para que o trabalho pudesse indicar áreas e ações prioritárias, a Bacia foi subdividida em 8 microbacias hidrográficas, conforme apresentado na Figura 1.

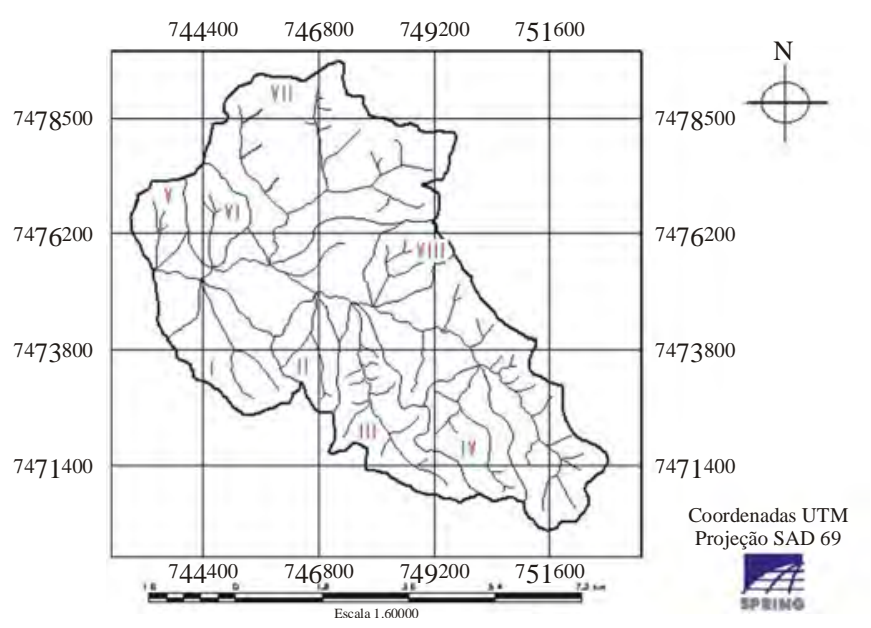

Figura 1. Limite e rede de drenagem da bacia experimental do Rio Claro e suas microbacias

Para embasamento teórico, fez-se uma extensa revisão literária sobre os principais fatores de ameaça aos recursos naturais no campo, conceitos e importância da conservação da natureza e como conservar, na prática, água, solo e biodiversidade, de forma integrada e de maneira sustentável.

Para a realização do diagnóstico ambiental tomou-se como referência a análise da deterioração ambiental a partir de três diagnósticos fundamentais: físico-conservacionista, socioeconômico e da qualidade ambiental.

O diagnóstico físico-conservacionista foi elaborado a partir de técnicas de sensoriamento remoto e geoprocessamento com o uso do sistema de informação geográfica SIG-SPRING, utilizando-se mapas de drenagem, declividade e uso da terra. Por não existir um mapa detalhado dos solos da região optou-se por utilizar um mapa expedito, elaborado a partir de fotografias aéreas na escala 1:30.000, conforme descrito por Déstro (2006).

O mapa expedito da capacidade de uso foi elaborado através do cruzamento do mapa expedito dos solos com o mapa de declividade. As áreas de conflito numa microbacia hidrográfica ocorreram quando o uso atual da terra subestimou o mapa expedito da capacidade de uso do solo ou o recomendado pela legislação ambiental. Assim, os conflitos pelo uso da terra em relação à capacidade foram aqueles oriundos do manejo incorreto das atividades agrícolas, como agricultura em locais apropriados para pastagem, 
culturas perenes ou preservação; pecuária extensiva desenvolvida em locais restritos às culturas perenes ou preservação e culturas perenes presentes em áreas de preservação. Numa segunda etapa fez-se o cruzamento do mapa de uso atual da terra (Déstro \& Campos, 2006) com o mapa expedito de capacidade de uso. O mapa final conteve duas classes, uma denominada "Certo", onde o uso da terra estava de acordo com a capacidade de uso, e outra "Errado", com o uso subestimando a capacidade.

As áreas a reflorestar (conflitos de uso em relação à legislação) foram calculadas de duas formas distintas: a primeira através do cálculo da área necessária para completar os $20 \%$ de Reserva Legal não representados por matas ou capoeiras (excluiu-se desta análise o montante pertencente às Áreas de Preservação Permanente - APP's) e, a segunda, por meio da análise da cobertura vegetal em APP's, onde qualquer uso que não fosse água, solo inundável, capoeira e mata, estaria contraditório ao exigido em Lei e por isto, sendo apontado como área a ser reflorestada.

Obteve-se a porcentagem de deterioração de cada microbacia a partir da média das porcentagens de deterioração das áreas de conflito e a reflorestar. $\mathrm{O}$ índice de deterioração físico-conservacionista (IDFC) da bacia hidrográfica experimental do Rio Claro foi definido pela média aritmética das porcentagens de deterioração das microbacias hidrográficas selecionadas.

O diagnóstico socioeconômico foi realizado a partir de questionários, nos quais se avaliou, de forma quantitativa, a deterioração em três níveis: no social, que envolvia as condições básicas de vida; no econômico, que abordou a sustentabilidade econômica dos moradores e no tecnológico, que diagnosticou os principais fatores que levam ao aumento ou queda na produtividade rural.

Finalmente, o diagnóstico da qualidade ambiental, que também foi obtido através de questionários, priorizou avaliar o quanto os meios de vida e produção rural eram danosos ao meio ambiente.

Os questionários utilizados nos diagnósticos socioeconômico e da qualidade ambiental seguiram o modelo proposto pelo Centro Internacional de Desenvolvimento Integral de Águas e Terras - CIDIAT, Venezuela, 1987, adaptado por Rocha (1997), conforme descrito por Déstro (2006). A tabulação dos dados consistiu em agrupamentos dos códigos e identificação da média. A soma dos resultados resultou nos Índices de Deterioração Socioeconômica (IDSE) e da Qualidade Ambiental (IDQA), dadas pela seguinte equação:

$$
\mathrm{y}=\mathrm{ax}+\mathrm{b}
$$

em que:

y - unidade crítica de deterioração socioeconômica ou da qualidade ambiental, variando de 0 a 100 , o que equivale a 0 e $100 \%$ de deterioração, respectivamente;

x - valor significativo encontrado com a tabulação dos códigos

Os índices de deterioração socioambiental e da qualidade ambiental na bacia hidrográfica experimental do Rio Claro foram definidos pela média aritmética das porcentagens de deterioração das microbacias hidrográficas selecionadas.

A deterioração ambiental nas microbacias estudadas e na bacia experimental do Rio Claro foi obtida a partir da média dos três índices de deterioração: físico-conservacionista, socioeconômico e da qualidade ambiental, formando a Roda Viva da Deterioração Ambiental (Rocha, 1997). Conseguiuse, desta forma, identificar os principais fatores de agressão à Bacia estudada, além de mapear as principais vulnerabilidades a que a área estava sujeita. Todos os parâmetros descritos foram agrupados para nortear a escolha das melhores alternativas locacionais para as Reservas Legais na bacia experimental do Rio Claro.

\section{RESULTADOS E DISCUSSÃO}

\section{Diagnóstico físico-conservacionista}

Conseguiu-se avaliar, a partir do diagnóstico físico-conservacionista, os principais usos indevidos da terra relacionados à declividade do terreno e às áreas de preservação permanente, além de mapear e quantificar os diferentes usos (Figura 2).

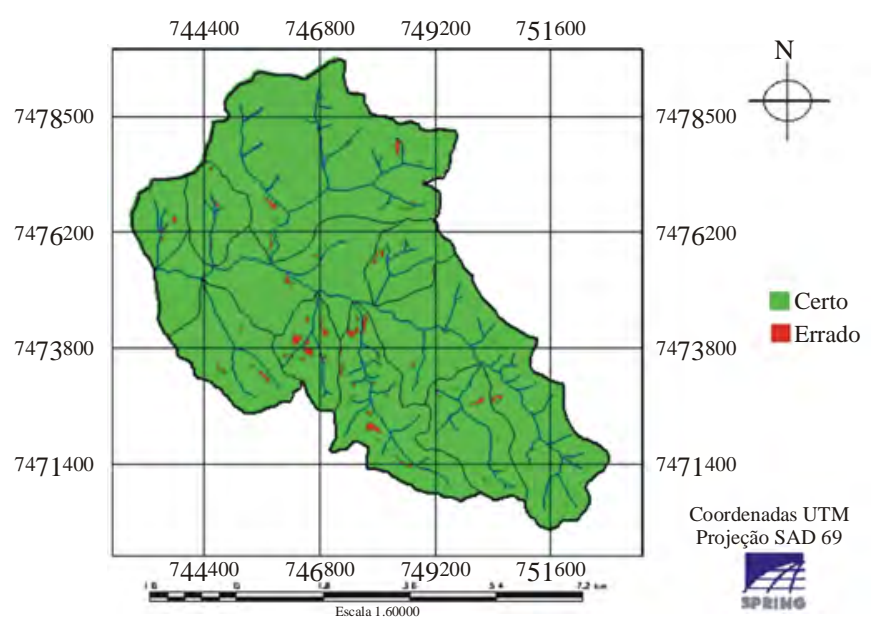

Figura 2. Mapa dos conflitos de uso na bacia experimental do Rio Claro

Nota-se que a área em conflito de uso não é expressiva, uma vez que ficou abaixo de $10 \%$ da área total da Bacia, todavia, essas regiões merecem atenção especial visto que estão concentradas em locais de solo arenoso e com declive acentuado.

No total foram mapeadas 67 nascentes na área de estudo além de todos os rios e corpos d'água presentes na carta topográfica, utilizados para o cálculo das áreas a reflorestar (Figura 3). Pela análise da deterioração das nascentes e margens de rios da Bacia, como um todo, notou-se que a parcela deteriorada quase alcançou $40 \%$. Vale lembrar que, para se chegar a este resultado, não foram contabilizadas apenas áreas de mata mas, também, capoeiras, solos inundáveis e água, que são usos naturais das APP's. Ecologicamente, nem toda Área de Preservação Permanente é propícia à formação de florestas. Trabalhos realizados por Dainese (2001) numa 
bacia vizinha à do Rio Claro mostraram resultados inferiores dos apresentados neste estudo, constatando-se que apenas $29,62 \%$ da área ao redor dos rios estavam constituídos de mata ciliar.

Para as áreas a reflorestar também se consideraram as parcelas de terra, com exceção das APP's, que faltassem para completar os $20 \%$ de Reservas Legais exigidos em Lei. Verificou-se, assim, que com exceção da primeira microbacia analisada, todas as restantes apresentaram déficit de área florestal, sendo que a V quase alcançou $15 \%$ de deterioração (Figura 3). Déficit de cobertura florestal relacionado às Reservas Legais também foi detectado em estudos realizados por Fidalgo et al. (2003) na Amazônia Oriental brasileira, por Jacovine et al. (2008) na Zona da Mata mineira e por Fagundes \& Gastal Júnior (2008) em um projeto de assentamento federal no Rio Grande do Sul.

Finalmente, com a média das porcentagens das áreas a reflorestar e dos conflitos de uso dos solos, chegou-se à deterioração físico-conservacionista (Figura 3). Nota-se que, em todas as microbacias analisadas, a deterioração ficou abaixo dos $20 \%$, sendo que as microbacias I e VIII apresentaram

A.

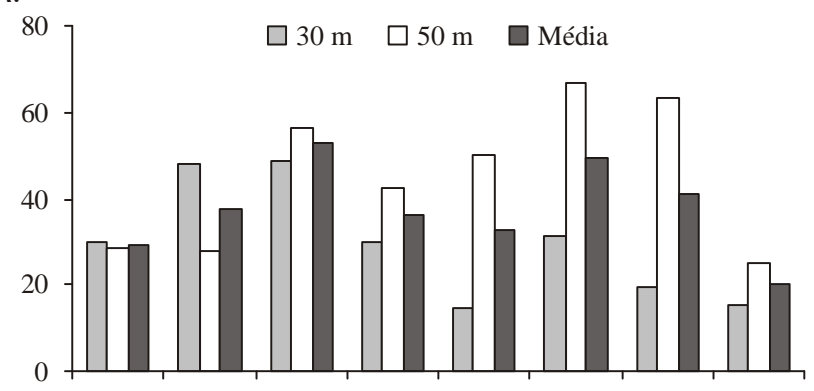

B.

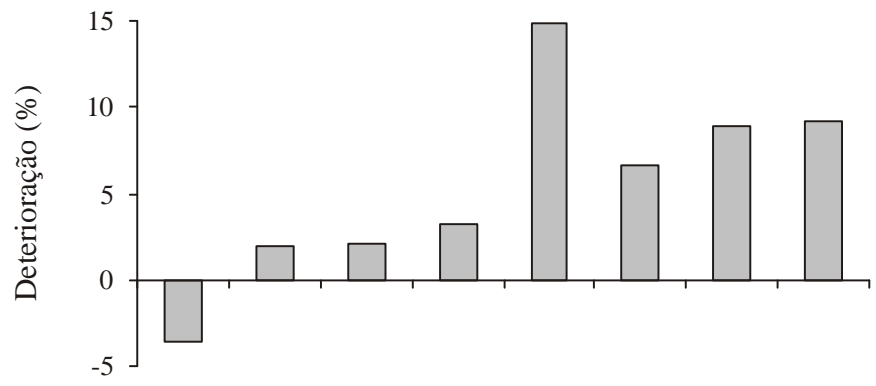

C.

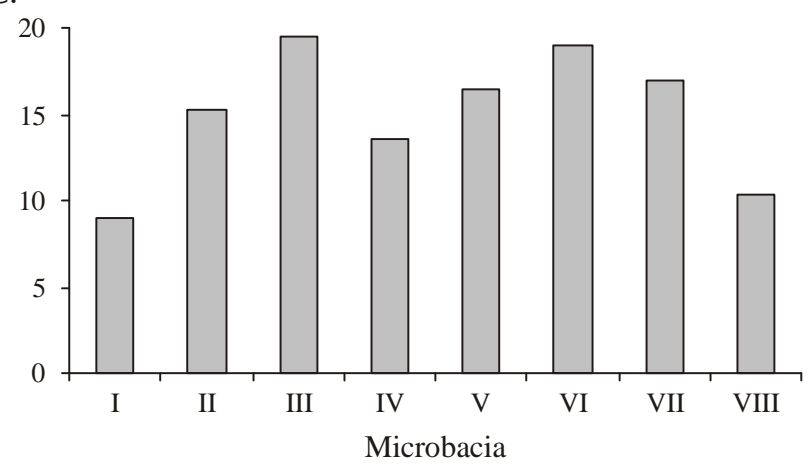

Figura 3. Resultados da análise físico-conservacionista: A. Uso indevido das áreas de nascente e margens de rios; B. Déficit de área equivalente às Reservas Legais; C. Índice de deterioração físico-conservacionista (IDFC) índices próximos a 10\%. Maiores deteriorações foram atribuídas as microbacias III e VI devido, principalmente, ao uso irregular das áreas de preservação permanente.

\section{Diagnóstico socioeconômico}

As principais vulnerabilidades da população na Bacia foram identificadas através do diagnóstico socioeconômico, seja no meio de vida, no saneamento básico ou nas debilidades de produção, registrados através do preenchimento de 59 questionários.

Os fatores deteriorantes do meio socioeconômico, representados em porcentagem de deterioração, estão contidos na Tabela 1, na qual se observa a contribuição da cada microbacia para a média da deterioração socioeconômica da bacia experimental do Rio Claro, representada pelo IDSE.

Nota-se que, as microbacias I e VI, por apresentarem grande representatividade de propriedades monocultoras e em desuso, acabaram se destacando negativamente nos fatores social e econômico; a microbacia III teve o melhor desempenho dentre todas as microbacias analisadas nos fatores social e econômico enquanto as microbacias VI e VIII tiveram destaque positivo no fator tecnológico; verificou-se, também, que a microbacia IV sempre apresentou uma deterioração acima da média, nos três fatores socioeconômicos analisados.

Tabela 1. Índice de deterioração socioeconômica (IDSE) com seus fatores deteriorantes e índice de deterioração da qualidade ambiental (IDQA) na bacia experimental do Rio Claro (RC) e em suas microbacias

\begin{tabular}{cccccc}
\hline & \multicolumn{3}{c}{$\begin{array}{c}\text { Fatores deteriorantes do meio } \\
\text { socioeconômico }\end{array}$} & & \\
\cline { 2 - 3 } Microbacia & $\begin{array}{c}\text { Fator } \\
\text { IDSE } \\
\text { Social } \\
\text { (\%) }\end{array}$ & $\begin{array}{c}\text { Fator } \\
\text { Econômico } \\
\text { (\%) }\end{array}$ & $\begin{array}{c}\text { Fator } \\
\text { Tecnológico } \\
\text { (\%) }\end{array}$ & $\begin{array}{c}\text { IDQA } \\
\text { (\%) }\end{array}$ & \\
I & 68,4 & 60,8 & 42,1 & 59,4 & 37,8 \\
II & 33,8 & 46,2 & 36,8 & 38,7 & 47,2 \\
III & 30 & 44,2 & 36,3 & 36,4 & 38,9 \\
IV & 50 & 52,7 & 47,4 & 50,3 & 46,1 \\
V & 38,4 & 53,8 & 44,7 & 45,2 & 37,8 \\
VI & 67,2 & 55,8 & 34,2 & 55,2 & 38,9 \\
VII & 39,1 & 49,2 & 37,4 & 42,1 & 37,2 \\
VIII & 41,6 & 45,4 & 32,6 & 40,7 & 40,0 \\
RC & 46,1 & 51,0 & 39,6 & 46,2 & 40,5 \\
\hline
\end{tabular}

Em termos gerais, o fator econômico foi o que mais contribuiu para a alta deterioração socioeconômica na bacia do Rio Claro. Estudos desenvolvidos por Torres et al. (2007; 2009) e Pereira \& Barbosa (2009) também evidenciaram a predominância deste fator no cômputo da deterioração socioeconômica nas bacias hidrográficas dos córregos Alegria e Jacaré, em Uberaba, MG, e na microbacia Cabelo Nãotem, em São João do Rio do Peixe, PB.

\section{Diagnóstico da qualidade ambiental}

Elencaram-se, através do diagnóstico da qualidade ambiental, as principais ameaças às quais os recursos naturais estão sujeitos. $\mathrm{O}$ índice de deterioração da qualidade ambiental, obtido através de questionários, também foi apresentado na Tabela 1. 
Nota-se que, desta vez, as microbacias II e IV foram as que mais contribuíram para a deterioração ambiental na bacia experimental do Rio Claro, devido, sobretudo, ao manejo inadequado dos resíduos sólidos, descarte incorreto das embalagens de agrotóxicos e má conservação das estradas rurais; destaque positivo para a microbacia VII, com menor índice de deterioração da qualidade ambiental.

\section{Deterioração ambiental}

Finalmente, foram reunidas, para o cálculo da deterioração ambiental, as deteriorações físico-conservacionista, socioeconômica e da qualidade ambiental. Nota-se, na Figura 4, que a deterioração socioeconômica foi o fator de maior contribuição para a deterioração nas microbacias I, IV, V, VI e VII; já o da qualidade ambiental foi o que mais influenciou negativamente as microbacias II e III. A deterioração físico-conservacionista, ao contrário, ajudou a diminuir os valores da deterioração ambiental em todas as microbacias, uma vez que apresentou valores bem abaixo dos outros índices.

$\mathrm{O}$ índice de deterioração ambiental na Bacia Experimental do Rio Claro ficou abaixo dos 35\% (Figura 4), e foram as microbacias IV e VI, respectivamente, as que mais contribuíram negativamente para este resultado. Destaques positivos para as microbacias VIII, III e VII, que apresentaram as menores taxas de deterioração ambiental.

\section{Diagnóstico qualitativo}

Em síntese, a Bacia Experimental do Rio Claro foi caracterizada, basicamente, por apresentar pequenas propriedades rurais, muito embora atividades outras como reflo-

A.

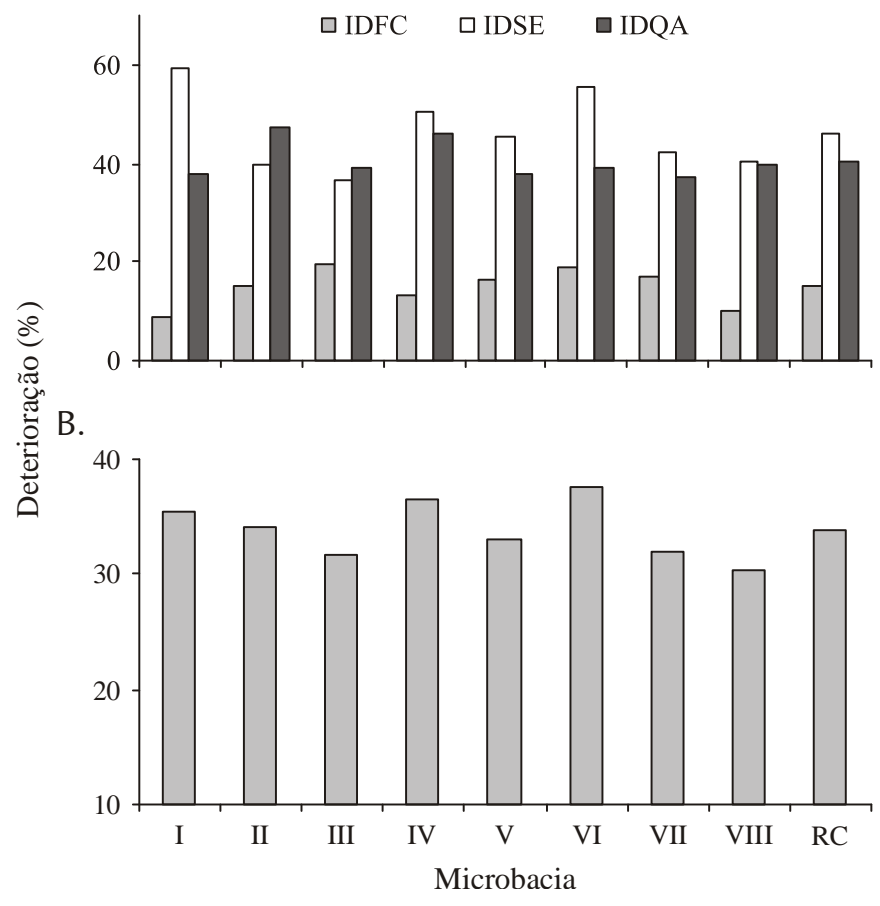

Figura 4. Índices de deterioração nas microbacias estudadas e na bacia experimental do Rio Claro. A. Índices de deterioração físico-conservacionista (IDFC), socioeconômico (IDSE) e da qualidade ambiental (IDQA); B. Índice de deterioração ambiental restamento com eucalipto e plantações de cana-de-açúcar manejadas por grandes indústrias, já ocupavam grande parte da paisagem. A pecuária bovina extensiva, voltada para o mercado de leite e de carne, foi a atividade que ocupou a maior parte da área e, como reflexo disto, notou-se que as áreas de mata estiveram muito abaixo do exigido em lei e não foram raros os casos de atividade econômica dentro das áreas protegidas.

Para Campos et al. (2004), o alto índice de uso da terra por pastagens, capoeiras, reflorestamento e matas reflete a predominância de solos arenosos com baixa fertilidade. Em outros estudos na região também houve predomínio da cobertura do solo por pastagens, como nos trabalhos realizados por Ribeiro (1998) e Dainese (2001).

De forma geral, os moradores da região se mostraram carentes de alternativas de informação, tratamento de água adequado, tendo que enfrentar altas incidências de pragas e baixa diversificação na produção, embora tenha sido comum a presença de hortas e pomares em quase todas as unidades produtivas. A maior parte das unidades não apresentou pocilgas ou aviários.

A população de jovens registrada foi alta, visto que grande parte dos moradores estava em idade escolar, o que garante infraestrutura básica de transporte por parte das prefeituras; a população, de modo geral, dispunha de bons serviços de saúde e todos tinham acesso à energia elétrica.

Quase a totalidade dos moradores utilizava fossas para eliminação de esgotos, o descarte das embalagens de biocidas se dava conforme previsto em Lei, embora o manejo de resíduos sólidos se desse, em grande parte, de maneira indevida.

A condição das estradas rurais foi avaliada pelos moradores como média a boa mas, neste quesito, notou-se o reflexo da sazonalidade, ou seja, maiores problemas eram enfrentados nos períodos chuvosos. A presença de voçorocas dentro das propriedades rurais foi classificada como de baixa incidência.

Em relação ao manejo agropecuário e com exceção das propriedades monocultoras de cana-de-açúcar, não se notou o uso frequente do fogo; rara também foi a unidade em que se registrou o uso de bombas para recalque de água visando à atividade agropecuária, mostrando que a vazão na Bacia estudada era pouco alterada por tal prática.

Poucas foram as áreas de mata nativa encontradas, com exceção das situadas em relevo muito íngreme; mais raro ainda foi encontrar mata ciliar ou medidas de proteção das matas nativas ao pisoteio do gado, o que reflete a falta de informação e o baixo nível de consciência dos proprietários rurais na região, como também observado por Gomes et al. (2007) em Minas Gerais. Em relação às Reservas Legais, notou-se enorme desconhecimento deste tema por parte dos produtores rurais.

\section{Propostas para implantação de reservas legais}

A descrição a seguir é fruto de um exercício a partir do diagnóstico ambiental realizado e dos conhecimentos científicos adquiridos através da revisão literária. Ressalta-se que a escolha final das melhores alternativas locacionais para as 
Reservas Legais deve advir de amplas discussões entre os comitês de bacias, técnicos extensionistas e, logicamente, entre os produtores rurais, principais atores das ações no meio rural; deve, também, ser apoiada na interrelação de aspectos básicos como o econômico, ambiental e cultural, uma vez que interferirão no grau de organização e união dos proprietários das terras e nos moradores da bacia hidrográfica (Santos et al., 2007).

Segundo o $3^{\circ}$ parágrafo do artigo 16 da Medida Provisória 2.166-67 de 2001, que altera o Código Florestal (LF 4.771/65), quando ressalta que: "para cumprimento da manutenção ou compensação da área de Reserva Legal em pequena propriedade ou posse rural familiar, podem ser computados os plantios de árvores frutíferas ornamentais ou industriais, compostos por espécies exóticas, cultivadas em sistema intercalar ou em consórcio com espécies nativas." Desta maneira, foi considerada pequena propriedade rural aquela com área inferior a 30 ha e cuja propriedade ou posse rural fosse explorada mediante o trabalho pessoal do proprietário ou posseiro e de sua família, admitida a ajuda eventual de terceiros e cuja renda bruta fosse proveniente, no mínimo, de $80 \%$ de atividade agroflorestal ou extrativismo. Ainda de acordo com a Medida Provisória (artigo 44), a recomposição da Reserva Legal pode ser feita mediante plantio temporário de espécies exóticas como pioneiras, transformando-se em uma alternativa de renda ao produtor e um incentivo à restauração.

\section{Microbacia I}

A microbacia I mostrou-se, em grande parte, propícia à agricultura. Por ter apresentado predomínio de monoculturas de cana-de-açúcar, acabou tendo alta deterioração socioeconômica, porém com alta produtividade e baixa deterioração da qualidade ambiental. A presença significativa de matas nativas contribuiu para o baixo índice de deterioração físico-conservacionista.

\section{Recomendações de manejo}

Esta microbacia apresentou a vantagem de possuir fragmentos florestais relativamente grandes se comparados a outros da região, embora esses estejam isolados e distantes da rede de drenagem. Neste caso, a reserva legal deve ser constituída por floresta nativa, uma vez que a microbacia I é formada por propriedades de médio porte.

Em uma primeira ação de manejo deve-se verificar se cada propriedade possui a porcentagem mínima de $20 \%$ e, caso necessite de recomposição, deve-se priorizar as áreas entre os fragmentos. A técnica de recomposição a ser utilizada pode, a princípio, ser a regeneração natural, pois a área pode apresentar boa capacidade de resiliência; as áreas ocupadas por capoeiras podem ser aproveitadas para recomposição, pois, além de apresentarem predisposições ecológicas, estão próximas aos fragmentos.

\section{Microbacia II}

A microbacia II apresentou baixa deterioração social e econômica, predominando atividades voltadas para as culturas anuais e pecuárias. O saneamento ambiental local foi um dos fatores mais preocupantes, sobretudo em relação ao descarte dos resíduos sólidos e tratamento de esgoto; foi a bacia que mais se destacou negativamente na variável educação. Em relação ao meio físico, a probabilidade de enchentes é baixa, uma vez que seu relevo foi considerado com declive mais acentuado em comparação com as outras microbacias; foi, também, uma microbacia preocupante em relação às restrições de uso dos solos, à baixa quantidade de matas e ao intenso uso irregular das margens dos rios.

\section{Recomendações de manejo}

Esta microbacia merece especial atenção nas ações voltadas ao social. Antes de qualquer medida ambiental, os tomadores de decisão devem buscar formas para melhorar as condições de saneamento básico e educação dos moradores. Sanado este problema, a população estará mais consciente e ativa quanto ao seu papel na melhoria da qualidade ambiental regional.

Como a região sul desta microbacia apresentou sérias restrições relacionadas ao uso da terra, o trabalho de restauração deve ser ali iniciado; ao contrário da microbacia I, esta microbacia não apresentou quantidade significativa de matas nativas, o que dificulta o processo de regeneração natural, todavia, o enriquecimento das capoeiras com espécies frutíferas e atrativas da fauna silvestre pode ser uma boa alternativa ao processo de restauração ambiental. Os pomares localizados nas pequenas propriedades na região sudeste da microbacia II podem servir de "trampolim ecológico", conectando os fragmentos florestais das microbacias II e III. Santos et al. (2007) sugerem a recuperação das áreas de pastagem em relevo ondulado a forte-ondulado através do plantio de árvores em faixas de retenção, o que pode ser uma alternativa viável para esta microbacia.

\section{Microbacia III}

A microbacia III se destacou de forma positiva, nas variáveis socioeconômicas, principalmente naquelas relacionadas ao saneamento básico. É uma bacia que requer cuidados em relação às erosões devido à alta declividade do terreno; em virtude de possuir grande parte de sua área destinada à prática pecuária, foi uma das que apresentou maiores problemas relacionados ao uso indevido da área de $30 \mathrm{~m}$ ao redor dos rios, ocasionando alta deterioração físico-conservacionista. Os fatores socioeconômicos contribuíram para a microbacia III a apresentar baixo valor de deterioração ambiental.

\section{Recomendações de manejo}

A microbacia III, por apresentar grande quantidade de pequenas propriedades, tem papel-chave no aumento da permeabilidade da matriz entre fragmentos através das árvores frutíferas dos pomares e daquelas dispersas na pastagem. Como na região foi observada uma área de mata maior que 30 ha ao redor do curso d'água principal, este fragmento pode ser alvo da conservação na microbacia, mas, para sua sustentabilidade, é fundamental sua conexão com fragmentos vizinhos. A área de capoeira marginal pode ser restaurada se a área nuclear de mata for aumentada significativamente, passando a ter formato mais próximo do circular. 
As margens dos rios, bastante deterioradas pelas pastagens, devem ser alvo de recuperação nesta microbacia, visto que, além de melhorar a qualidade da água, facilitarão o fluxo das espécies. Como descrito no parágrafo $7^{\circ}$ da Medida Provisória 2.166-67 de 2001, é permitido o acesso de pessoas e animais nas áreas de conservação permanente para obtenção de água, desde que não haja supressão da vegetação e a regeneração e manutenção da vegetação, em longo prazo, não sejam comprometidas.

\section{Microbacia IV}

Contrapondo-se à microbacia III, a microbacia IV apresentou alta deterioração econômica e tecnológica, com destaques negativos na variável formação de organizações e assistência técnica; o fator escolaridade foi um dos melhores resultados na avaliação geral entre as microbacias analisadas.

A alta deterioração da qualidade ambiental obtida pode ser explicada pela elevada deterioração econômica e tecnológica, oriunda da falta de conhecimento técnico para a utilização correta do solo, fator que se agrava por se tratar de uma das microbacias com maiores restrições de uso. Este fato pode estar relacionado, ainda, com os intensos problemas de produtividade e manutenção de estradas, fator de destaque nos questionários.

A declividade média elevada tornou esta microbacia uma das menos propícias à formação de enchentes, porém, em contrapartida, cuidados devam ser tomados em relação à formação de erosões. Pastagem e culturas anuais dominaram a paisagem.

\section{Recomendações de manejo}

A microbacia IV, formada basicamente por médios proprietários, deve ter suas reservas legais formadas, necessariamente, por florestas nativas. Como apresenta fragmentos e capoeiras próximos ao canal de drenagem principal, as reservas poderão ter importante papel no aumento das áreas de mata através do enriquecimento ou adensamento das capoeiras, formando uma faixa protetora ao redor das matas.

O processo de restauração ambiental pode ser iniciado nas áreas restritivas de uso pelo mapa expedito da capacidade, uma vez que são bastante significativos. Para que o processo de recuperação seja duradouro, deve-se promover, concomitantemente, um trabalho intenso de mobilização e organização social pelos extensionistas, de modo que os proprietários rurais participem ativamente das propostas de planejamento e melhoria da sua própria qualidade de vida (Souza, 2009).

\section{Microbacia V}

A microbacia $V$ também apresentou alta deterioração econômica e tecnológica. O baixo uso de insumos é um dos fatores que pode estar diretamente relacionado com a baixa produtividade detectada. Por outro lado, a microbacia V apresentou baixa deterioração da qualidade ambiental e pouco uso antrópico nas áreas de $30 \mathrm{~m}$ ao redor dos rios. Pastagens e culturas anuais foram os usos de maior domínio, ao contrário das matas destinadas às reservas legais, que apresentaram concentração bem abaixo dos $20 \%$ exigidos em lei.

\section{Recomendações de manejo}

$\mathrm{Na}$ microbacia $\mathrm{V}$ o manejo ambiental deverá ser o mais laborioso, uma vez que são poucos os fragmentos de mata nativa presentes na área. Uma alternativa mais viável pode ser a recuperação da mata ciliar, uma vez que apresentou um dos melhores índices de conservação se comparada com as outras microbacias. Com a conservação das margens dos rios poderá ser formado um corredor de ligação com as áreas florestais de outras microbacias e os pomares, muito comuns nas pequenas propriedades da região, poderão ocupar, legalmente, as áreas destinadas às reservas legais, auxiliando no fluxo gênico da biodiversidade local.

\section{Microbacia VI}

A microbacia VI apresentou-se problemática em vários aspectos. Em trechos isolados, de alta declividade, as erosões passaram a ser preocupantes, embora tenham sido poucas as áreas que apresentassem restrições quanto ao uso da terra. O predomínio da monocultura da cana-de-açúcar refletiu diretamente na alta deterioração socioeconômica, embora a boa estrutura tecnológica tenha elevado diretamente os índices de produtividade. Outro ponto negativo de destaque foi o elevado uso de fogo e biocidas, com reflexos diretos na baixa diversidade de fauna silvestre levantada nos questionários. As nascentes desta microbacia estavam entre as mais desprotegidas, contribuindo para elevar ainda mais os valores de deterioração físico-conservacionista. A microbacia VI foi a que apresentou maior deterioração ambiental.

\section{Recomendações de manejo}

Como esta microbacia apresentou propriedades de médio porte, é possível vislumbrar a recuperação de algumas áreas de capoeira, possibilitando a formação de refúgios para a fauna remanescente; para que a fauna se restabeleça por completo, deve-se dar maior atenção aos cuidados com biocidas e evitar o uso de fogo, especialmente na cultura da cana-de-açúcar.

Mais uma vez, a recuperação das matas ciliares é recomendada pois elas servirão de corredores ecológicos para a biodiversidade regional; todavia, as nascentes devem ser o foco inicial da recuperação ambiental.

\section{Microbacia VII}

A baixa deterioração da qualidade ambiental foi destaque positivo na microbacia VII. A paisagem, embora dominada por reflorestamentos, apresentou uma parcela considerável de pastagens e fragmentos florestais conservados. Esta microbacia possuiu baixa declividade média, com os menores riscos de erosão em relação às outras microbacias; grande parte de suas nascentes estava desprotegida, muito embora a microbacia tenha apresentado uma das menores taxas de conflito de uso quanto à capacidade de uso dos solos.

\section{Recomendações de manejo}

A microbacia VII se destacou por apresentar os maiores fragmentos mais próximos do formato circular, alcançando a área total de 45 ha. Esses fragmentos foram detectados em grandes propriedades e, entre eles, inúmeras pequenas propriedades. Como descrito para as microbacias II e V, as 
reservas legais formadas por árvores frutíferas, como pomares, poderão facilitar o deslocamento da fauna entre fragmentos, auxiliando o fluxo genético de plantas e animais. Para Rodrigues et al. (2007), os sistemas agroflorestais também surgem como boa alternativa na recuperação das áreas de Reserva Legal em propriedades rurais, podendo gerar renda ao produtor, graças ao consórcio agrícola.

Os reflorestamentos, comuns nesta microbacia, poderão ajudar ainda mais a biodiversidade local se forem mantidas as áreas de sub-bosque, camada arbustiva de plantas nativas que cresce naturalmente em florestas plantadas, úteis para o aumento a permeabilidade ao deslocamento da fauna local. A recuperação e a proteção das nascentes também devem ser encaradas como prioridade, uma vez que se encontram desprotegidas e influenciam diretamente na qualidade da água disponível.

\section{Microbacia VIII}

A microbacia VIII apresentou aspecto curioso: se, por um lado, as APP's nas margens dos rios e nascentes estavam mais bem protegidas, por outro, o déficit em relação aos $20 \%$ mínimos de Reserva Legal foi grande; o alto uso de insumos agrícolas e reduzido número de erosões tiveram reflexo direto na baixa deterioração econômica e tecnológica com domínio, mais uma vez, da atividade pecuária extensiva no uso da paisagem.

\section{Recomendações de manejo}

Os dois fragmentos de mata remanescente em área de nascente podem ser o foco de conservação desta microbacia em que, a partir deles, poderão ser estruturados todos os projetos de recuperação através da regeneração natural ou pela formação de mudas. Devido aos custos elevados relacionados aos projetos de recuperação ambiental, Rodrigues et al. (2007) recomendam a implantação de um processo participativo, no qual os custos poderiam ser reduzidos com a geração de receitas já na implantação do plantio (consórcio com culturas agrícolas), e, futuramente, com o manejo sustentável do componente arbóreo. A presença de trechos de mata ciliar e nascentes bem conservados pode ser fator relevante na restauração desta microbacia, desde que os prováveis fatores de degradação sejam reduzidos ou eliminados.

\section{CONCLUSÕES}

1. O nível de deterioração na Bacia Experimental do Rio Claro foi considerado médio, influenciado principalmente pela alta deterioração socioeconômica.

2. Dentre as microbacias analisadas, a microbacia VI foi a que apresentou o maior nível de deterioração ambiental, devendo ser priorizada nas ações de manejo e recuperação ambiental.

3. Comprovou-se, através do estudo dos conflitos de uso da terra que, é possível reunir, de maneira satisfatória, informações inerentes à legislação ambiental e à capacidade de uso dos solos, muitas vezes trabalhadas de maneira isolada.
4. Constatou-se finalmente, a eficiência do software SIGSPRING, das imagens do satélite CBERS e da análise da deterioração ambiental no planejamento territorial de Reservas Legais, em uma escala de paisagem.

\section{LITERATURA CITADA}

Bertoni, J.; Lombardi Neto, F. Conservação do solo. São Paulo: Ícone, 1990. 355p.

Campos, S., Araújo Júnior, A. A. A.; Barros, Z. X.; Cardoso, L. G.; Piroli, E. L. Sensoriamento remoto e geoprocessamento aplicados ao uso da terra em microbacias hidrográficas, Botucatu, SP. Engenharia Agrícola, v.24, n.2, p.431-435, 2004.

Dainese, R. C. Sensoriamento remoto e geoprocessamento aplicado ao estudo temporal do uso da terra e na comparação entre classificação não-supervisionada e análise visual. Botucatu: UNESP. 2001. 186p. Dissertação Mestrado

Delalibera, H. C.; Weirich Neto, P. H.; Lopes, A. R. C.; Rocha, C. H. Alocação de reserva legal em propriedades rurais: do cartesiano ao holístico. Revista Brasileira de Engenharia Agrícola e Ambiental, v.12, n.3, p.286-292, 2008.

Déstro, G. F. G. Estudos para implantação de reservas legais: uma nova perspectiva na conservação dos recursos naturais. Botucatu: UNESP. 2006. 184p. Dissertação Mestrado

Déstro, G. F. G.; Campos, S. SIG-SPRING na caracterização do uso do solo a partir de imagens de satélite CBERS. Energia na Agricultura, v.21, n.4, p.28-35, 2006.

Fagundes, N. A.; Gastal Júnior, C. V. de S. Diagnóstico ambiental e delimitação de áreas de preservação permanente em um assentamento rural. Acta Scientiarum, v.30, n.1, p.29-38, 2008.

Fidalgo, E. C. C.; Crepani, E.; Duarte, V.; Shimabukuro, Y. E.; Pinto, R. M. da S.; Dousseau, S. L. Mapeamento do uso e da cobertura atual da terra para indicação de áreas disponíveis para reservas legais: estudo em nove municípios da região amazônica. Revista Árvore, v.27, n.6, p.871-877, 2003.

Gomes, N. M.; Faria, M. A. de; Silva, A. M. da; Mello, C. R. de; Viola, M. R. Variabilidade espacial de atributos físicos do solo associados ao uso e ocupação da paisagem. Revista Brasileira de Engenharia Agrícola e Ambiental, v.11, n.4, p.427-435, 2007.

Jacovine, L. A. G.; Corrêa, J. B. L.; Silva, M. L. da; Valverde, S. R.; Fernandes Filho, E. I.; Coelho, F. M. G.; Paiva, H. N. de. Quantificação das áreas de preservação permanente e de reserva legal em propriedades da bacia do Rio Pomba, MG. Revista Árvore, v.32, n.2, p.269-278, 2008.

Pereira, R. A.; Barbosa, M. de F. N. Diagnóstico socioeconômico e ambiental de uma microbacia hidrográfica no semiárido paraibano. Engenharia Ambiental, v.6, n.1, p.137-153, 2009.

Ribeiro, F.L. Sistemas de informações geográficas aplicados ao mapeamento dos usos atual e adequado na terra do Alto Rio Pardo, Botucatu, SP. Botucatu: UNESP. 1998. 144p. Dissertação Mestrado

Rocha, J. S. M. da. Manual de Projetos Ambientais. Santa Maria: UFMS, 1997. 423p. 
Rodrigues, E. R.; Cullen Jr., L.; Beltrame, T. P.; Moscogliato, A.V.; Silva, I. C. da. Avaliação econômica de sistema agroflorestais implantados para recuperação de reservas legais no Pontal do Paranapanema, São Paulo. Revista Árvore, v.31, n.5, p.941-948, 2007.

Santos, G. V.; Dias, H. C. T.; Silva, A. P. de S.; Macedo, M. de N. C. de. Análise hidrológica e socioambiental da bacia hidrográfica do Córrego Romão dos Reis, Viçosa, MG. Revista Árvore, v.31, n.5, p.931-940, 2007.

Souza, M. M. O. de. A utilização de metodologias de diagnóstico e planejamento participativo em assentamentos rurais: O diagnóstico rural/rápido participativo, DRP. Revista Em Extensão, v.8, n.1, p.34-47, 2009.
Tornero, M. T. Análise ambiental através de Sistema de Informação Geográfica (SIG), como subsídio ao planejamento do município de Maringá, PR. Botucatu: UNESP. 2000. 184p. Tese Doutorado

Torres, J. L. R.; Fabian, A. J.; Amaral, F. dos S.; Silva Sobrinho, J. B. F. da; Loes, L. F. C. A deterioração da ambiência numa microbacia da Área de Proteção Ambiental do Rio Uberaba. Global Science and Technology, v.2, n.1, p.7-21, 2009.

Torres, J. L. R.; Silva, T. R. da; Oliveira, F. G.; Araújo, G. S.; Fabian, A. J. Diagnóstico socioeconômico, ambiental e avaliação das características morfométricas da microbacia do Córrego Alegria em Uberaba, MG. Sociedade \& Natureza, v.19, n.2, p.89-102, 2007. 